\title{
The Technical Approach for Measuring the Performance of the Malaysian Shariah Stocks During the COVID-19 Outbreak
}

\author{
Noor Saif Muhammad Mussafi ${ }^{1,2,}$ Zuhaimy Ismail ${ }^{2, *}$ \\ ${ }^{1}$ Department of Mathematics, UIN Sunan Kalijaga Yogyakarta, Indonesia \\ ${ }^{2}$ Department of Mathematical Sciences, Universiti Teknologi Malaysia, Johor Bahru, Malaysia \\ *Corresponding author. Email: zuhaimyutm@gmail.com
}

\begin{abstract}
The COVID-19 outbreak affects all aspects of life including stocks trading. This paper aims to highlight the performance of Malaysian Shariah stocks during the COVID-19 outbreak by employing modified Reward to Variability (mRVAL) and EMA (Exponential Moving Average). The analysis of individual stocks started by mRVAL to consider the risk-adjusted return and followed by EMA to predict the buy or sell momentum. The dataset considers the historical price of the top-rated constituents of FTSE Bursa Malaysia EMAS Shariah Index among the three waves of the COVID-19 outbreak in Malaysia, particularly in 2020. The result shows that TPGC outperforms others in the risk-return ratio with a value of 0.0621 . Meanwhile, the buy signal of TPGC falls on October 1, 2020, while the selling momentums are suggested around a month before and after the buy signal. Overall, most of the shariah stocks showed a downward trend of volatility in 2020 compared to the previous year. However, TPGC (a health care sector) has surprisingly improved during the COVID-19 outbreak.
\end{abstract}

Keywords: COVID-19, Malaysian Shariah Stocks, mRVAL, EMA

\section{INTRODUCTION}

The Coronavirus disease (COVID-19) was first announced in Malaysia on January 25, 2020, which was recorded as the beginning of the first wave until the next three weeks [1]. The second wave has occurred on February 27, 2020, and ended on June 30, 2020. After that, starting September 8, 2020, Malaysia is fronting a bigger obstacle in handling COVID-19 in the third wave as the daily number of confirmed cases was rising significantly particularly contributed by two main clusters, i.e., the Benteng Lahad Datu and Tembok Kedah [2]. The government imposed the Movement Control Order (MCO) to suppress the transmission of COVID-19. Some level restrictions policies of MCO such as $\mathrm{CMCO}, \mathrm{RMCO}$, and the strictest one EMCO are implemented to deflate the curve of confirmed cases [3]. However, these efforts are no longer sufficient to control the circumstances especially with the presence of a delta variant that is almost twice more contagious than the Wuhan strain of SARS-CoV-2 [4]. At the end of May 2021, the Ministry of Health reported new cases of COVID-19 in Malaysia reached 8,290 so that the prime minister was forced to declare a nationwide lockdown. This situation is certainly not only damaging the health systems but also the economy of the country including stocks trading in Malaysia. The negative inflation of 1.2 percent in 2020, as reported by the Department of Statistics Malaysia, indirectly affects the overall stock market performance.

Many technical indicators can be used to analyze the performance of stocks in trading across a certain period. The Reward to Variability (RVAL), a measure of the expected return per unit of risk (standard deviation), initiated by William F. Sharpe, is the common risk-adjusted ratio [5], [6]. Many scholars have revealed its usefulness and enhanced RVAL to obtain better results [7]-[9]. For instance, Dowd [7] proposed modified RVAL (mRVAL) to avoid correlation problems encountered in the traditional RVAL. It is valid for any correlations, unlike RVAL that are valid only if the correlation is zero. Meanwhile, practitioners extensively used Exponential Moving Average (EMA) to investigate historical price trend direction over a certain period [10], [11]. EMA has a slightly better 
smoothing/accuracy ratio than Simple Moving Average [12]. In addition, Eiamkanitchat, Moontuy, \& Ramingwong [13] also recommend EMA as a suitable predictive indicator of trading, other than Moving Average Convergence Divergence, Relative Strength Index, Stochastic Oscillator, that consequently gains a promising profit (average earning and average hold days) in the Stock Exchange of Thailand. The difference between the current study and previous studies lies in the combination of mRVAL and EMA in such a way as to choose the proper portfolio and predict transaction momentum during the pandemic era.

This study captures the performance of Malaysian shariah stocks during the COVID-19 outbreak using a technical approach. The contribution of our paper is the exploitation of the mathematical properties of modified RVAL and EMA to evaluate the performance of Malaysian shariah stocks during the COVID-19 outbreak. These results are expected to provide insight for scholars or even potential traders in evaluating shariah stocks in the current situation, particularly during the pandemic period. For comparison, the performance of shariah stocks in the previous year will also be reviewed. The remainder of the paper is structured in the following manner. Section 2 outlines the data treated and methods used to analyze the performance of stocks. Section 3 focuses on the main results and discussion. Finally, Section 4 concludes the study.

\section{MATERIALS AND METHODS}

\subsection{Materials}

Referring to the technical approach, some mathematical properties related to this study are modified RVAL (mRVAL) and EMA. Dowd [7] initiates modified RVAL by employing Value at Risk (VaR) rather than standard deviation of return as risk measure divisor. Let $R_{i}$ be return on stocks $i$ and $R_{f}$ be risk-free rate, the mRVAL is calculated as

$$
m R V A L=\frac{R_{i}-R_{f}}{V a R}
$$

where $\operatorname{VaR}_{\alpha}(X)$ is a lower $\alpha$-percentile of the random variable $X$ for $\alpha \in[0,1]$. Meanwhile, EMA uses the rule of exponential number in making weighting features in time series so it's never reaching zero [10]. Furthermore, EMA on a treated date $t$ can be formulated as

$$
E M A_{t}=\hat{\alpha}\left(C-E M A_{t-1}\right)+E M A_{t-1}
$$

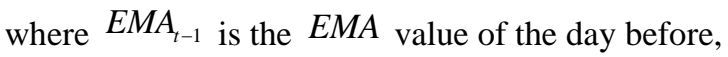
$C$ shows the current closing price of stocks, and $\hat{\alpha}$ represents the weighting degree or an arbitrary smoothing constant between null and one, i.e.,

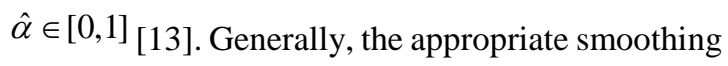
constant $\hat{\alpha}$ is calculated as

$$
\hat{\alpha}=\frac{2}{n+1}
$$

Moreover, let $P_{i}$ be the closing price of stocks on day $i$. The initial value $E M A_{t}$ is calculated by employing Simple Moving Average (SMA) on a treated date $t$ which is considered as

$$
S M A_{t}=\frac{\sum_{i=1}^{n} P_{i}}{t}
$$

\subsection{Methods}

A dataset used in this study is the Malaysian Shariah Stocks listed in FTSE Bursa Malaysia EMAS Shariah Index. It is the largest shariah indices in Malaysia with 223 constituents and has been registered as a Shariah-compliant investment product. Constituents listed in FTSE Bursa Malaysia EMAS Shariah Index are screened by Shariah Advisory Council (SAC) of Malaysia and an independent firm of Yasaar Ltd under a stringent set of rules The empirical data is limited to the top ten stocks or constituents released by FTSE Russel in December 2020. The ranking list is based entirely on the total market value of the company's outstanding shares, i.e., market capitalization [14].

The data analysis of this study deals with a technical approach. The detailed procedure is given as follow. First, we evaluate the performance metric of shariah stocks by employing mRVAL proposed by Dowd [7], to identify the best risk-return ratio among several stocks. After that, we observe trends of charts of stocks and investigate them using a trend indicator, i.e., Exponential Moving Average (EMA), to predict the proper time to buy, hold or 
sell stocks. The periods used in this short-term trend are 12-days and 26-days. Lastly, we compare the performance of the annual stocks between pre- and mid-outbreak.

\section{RESULTS AND DISCUSSION}

This section reveals the results and discussion correspond to the objectives of the study specified in the introduction, namely technical approach. In addition, the annual stock performance before and during the outbreak will also be compared.

\subsection{Risk-adjusted return}

The sample collected in this study is secondary data that covers the daily closing price of 10 stocks with the best market capitalization listed in FTSE Bursa Malaysia Emas Shariah Index (published by investing.com) during January-December 2020. In addition, interest rate data released by Bank Negara Malaysia is used as the proxy of risk-free rate during the same period.

The risk-free rate $R_{f}$ assumed in this study is the interest rate issued by the official website of Bank Negara Malaysia during the year 2020. Due to the observation, the average interest rate is $2.1184 \%$ per month [15]. Because the historical price of stocks analyzed is daily-based data, the monthly interest rate must be divided by 30 so that a daily interest rate of $0.070613 \%$ is obtained.

Under the daily prices, geometric returns were computed and an average return $R_{i}$ of 249 days was calculated for each stock. Meanwhile, a risk measure of $\mathrm{VaR}$ with a confidence level of $95 \%$ was also calculated for each stock as well so that the riskadjusted return of mRVAL can be considered (Table $1)$.

Table I. The Risk-Adjusted return performance of constituents listed on ftse bursa malaysia emas shariah index

\begin{tabular}{|l|l|l|l|l|l|l|}
\hline $\begin{array}{l}\text { Rankin } \\
\mathbf{g}\end{array}$ & Code & Constituents & Sector & $\boldsymbol{R}_{\boldsymbol{i}}$ & $\begin{array}{l}\text { VaR } \\
(\mathbf{9 5 \%})\end{array}$ & $\mathbf{m R V A L}$ \\
\hline 1 & TPGC & Top Glove Corp. & Health Care & $0.55375 \%$ & $7.7791 \%$ & 0.0621071 \\
\hline 2 & HTHB & Hartalega Holdings Bhd & Health Care & $0.33041 \%$ & $5.6259 \%$ & 0.0461777 \\
\hline 3 & PMET & $\begin{array}{l}\text { Press Metal Aluminium } \\
\text { Holdings }\end{array}$ & Metals and Mining & $0.22903 \%$ & $4.5107 \%$ & 0.0351191 \\
\hline 4 & PCGB & $\begin{array}{l}\text { PETRONAS Chemicals } \\
\text { Group Bhd }\end{array}$ & Chemicals & $0.00163 \%$ & $4.8959 \%$ & -0.0140897 \\
\hline 5 & $\begin{array}{l}\text { DSO } \\
\text { M }\end{array}$ & Digi.com & Telecommunications & $0.03183 \%$ & $2.5674 \%$ & -0.0151079 \\
\hline 6 & SIME & Sime Darby Plantation & Food Producers & $0.01241 \%$ & $2.9209 \%$ & -0.0199275 \\
\hline 7 & AXIA & Axiata Group Bhd & Telecommunications & $-0.04194 \%$ & $4.3521 \%$ & -0.0258630 \\
\hline 8 & DIAL & Dialog Group & Oil Equipment & $-0.00349 \%$ & $2.8632 \%$ & -0.0258815 \\
\hline 9 & IHHH & IHH Healthcare & Health Care & $-0.00510 \%$ & $2.9228 \%$ & -0.0259039 \\
\hline 10 & TENA & Tenaga Nasional & Electricity & $-0.09840 \%$ & $2.3071 \%$ & -0.0732580 \\
\hline
\end{tabular}

It can be seen in Table 1, constituents of TPGC and HTHB, operating the Health Care Equipment \& Services sector, achieve the top two in generating the return that is relatively balanced with the risk value characterized by the investment over a given period.

\subsection{Prediction of buying/selling momentum}

The prediction in this part deals with the best risk-adjusted return considered in the earlier subchapter, TPGC. The procedure in EMA starts by analyzing the original daily historical close price compared to the moving average that places a weight on the recent data points exponentially. As with all moving averages, this technical approach is used to produce buy and sell signals based on a bullish crossover and a bearish crossover from the original historical price. In detail, an ascending momentum occurs when a short-term EMA (12days) crosses above a longer-term EMA (26-days), otherwise, there will be downhill momentum.

As can be seen in Figure 1, indication signals to buy or sell of TPGC use a short period of EMA-12 (red line) and a long period of EMA-26 (red line) as 
suggested by [16], against the daily historical price (black dot). Buy signal, concerning bullish, is activated when the EMA-12>EMA-26 or red lines crosses above the blue line. Conversely, sell signal, with regard to bearish, is enabled when the EMA$12<$ EMA-26 or red line crosses below the blue line (Figure 1). Moreover, the interval period between buying and selling signals, shown by vertical lines, indicates holding momentum. Figure 1 also implies that a bullish crossover or the proper time to buy stocks (green vertical line) falls in early October 2020, particularly flanked by two selling times (purple vertical line). Accordingly, the evaluation of TPGC using EMA successively yields an average return of $0.60973 \%$, risk of $3.08905 \%$, and average hold of 81.75 days.

\subsection{Comparison of stocks performance in the pre and mid-outbreak}

We assume that the pre-outbreak falls in 2019 and the mid-outbreak represents the entirety of 2020. The samples are the constituents with the highest value and the lowest value of mRVAL, i.e., TPGC and TENA. Moreover, the comparison will cover some widespread indicators like average return, risk (VaR), mRVAL, average price, and an average of selling volume (Table 2).

TPGC gained quite a large profit or return in 2020 with a difference of $2,7551 \%$ increase compared to the previous year (Table 2). This data is directly proportional to the increase in the average stocks price and selling volume in 2020 (Figure 2a). Such a situation may be caused by increasing market sentiment towards the necessity for health care equipment during the pandemic.

On the other hand, TENA shows a decline in stock prices and average returns. Nevertheless, its selling volume still showed an increase of more than $12 \%$ which means it confirms the existence and continuity of TENA and the fact that it stands in the highest market capitalization (Table 1, Table 2 and Figure $2 b$ ). In terms of volatility or dispersion of return, most of shariah stocks listed in Table 1 are riskier during the mid-outbreak (orange line) than the pre-outbreak (blue line) (Figure 3). It can also be observed that only PMET manages to reduce the risk almost twofold under difficult circumstances.

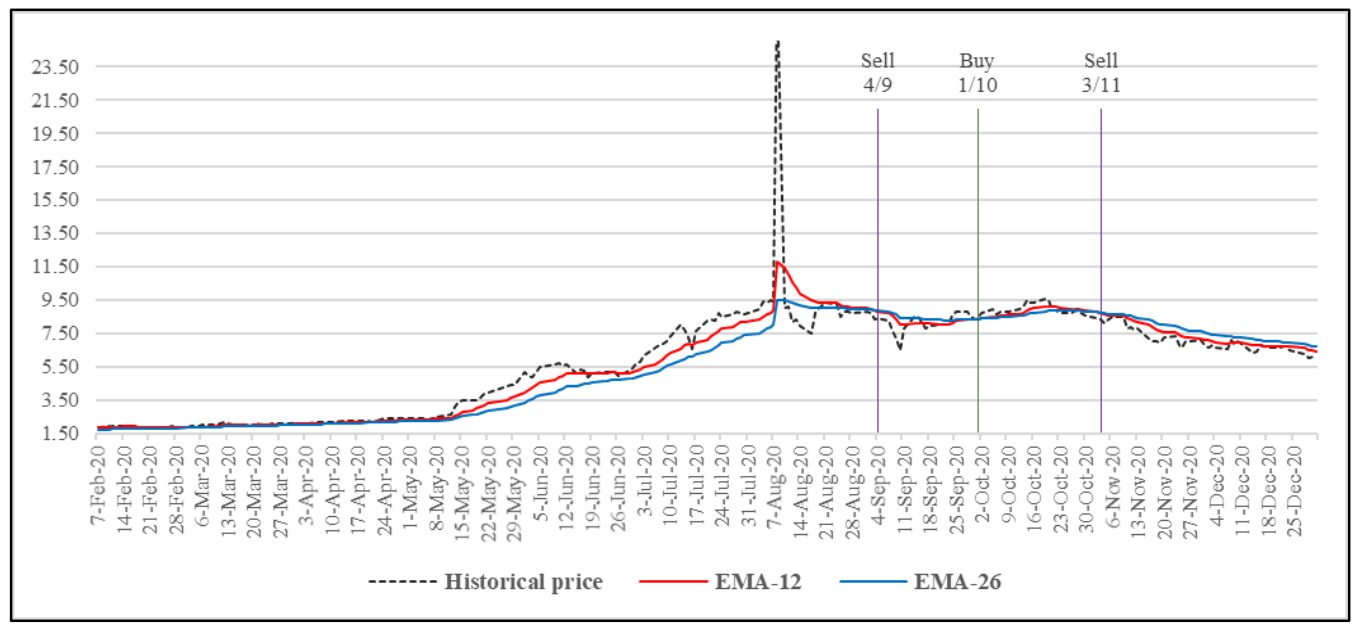

Figure 1. The performance of TPGC generated by EMA analysis in 2020 

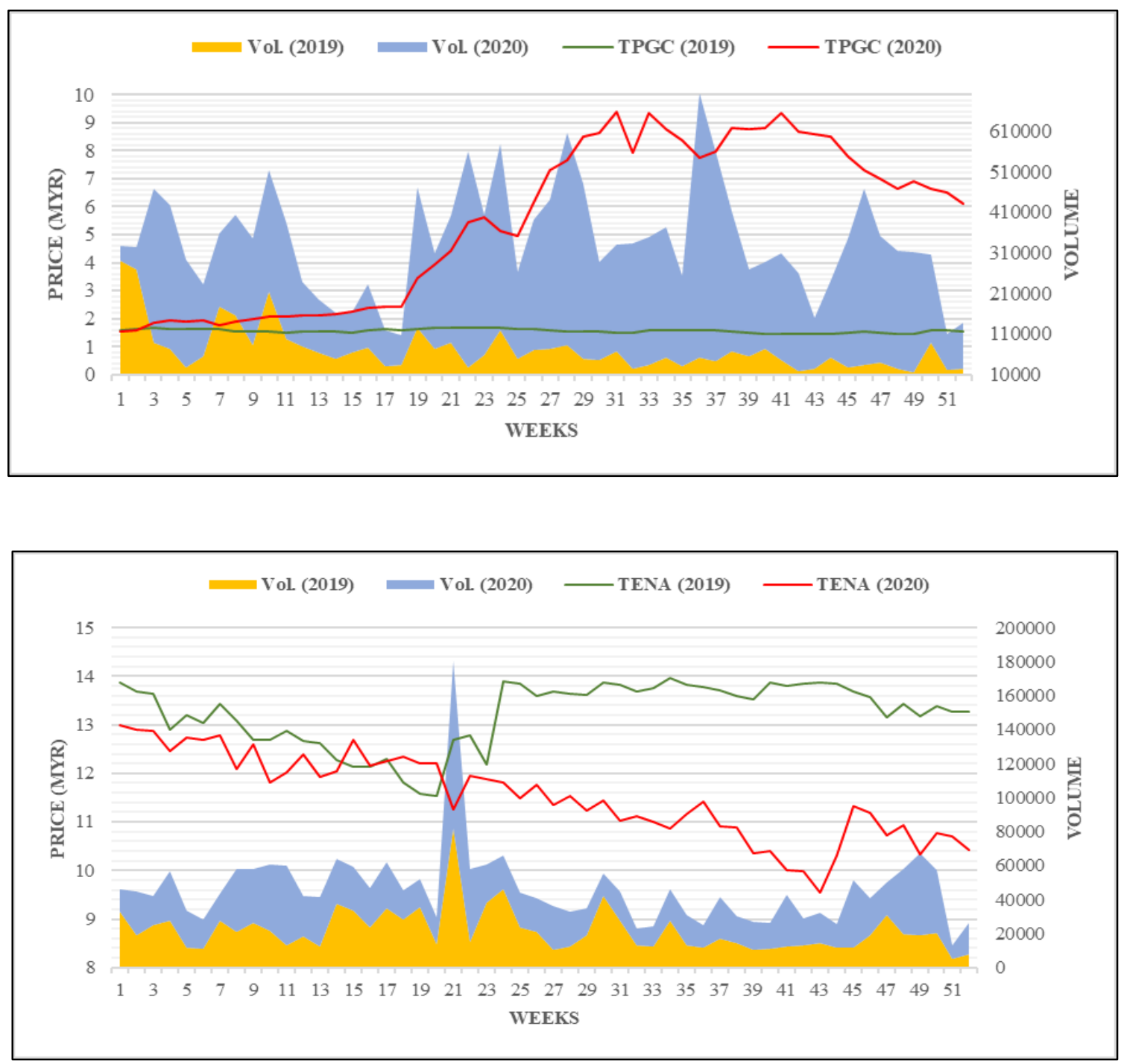

Figure 2. The price movement trend against selling volume in the pre and mid-outbreak for (a) TPGC (top graph) and (b) TENA (bottom graph) 


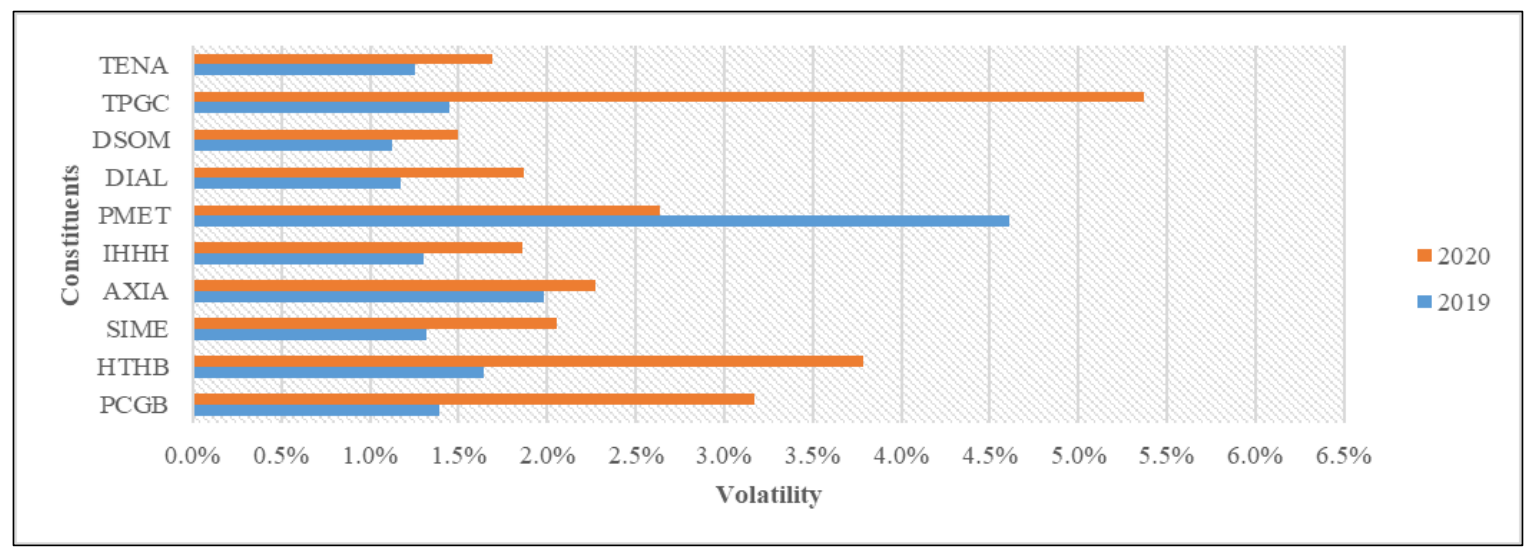

Figure 3. The volatility trend of shariah stocks in the pre and mid-outbreak

Table 2. Annual stock performance (2019 vs 2020)

\begin{tabular}{|c|c|c|c|c|}
\hline \multirow{2}{*}{ Indicators } & \multicolumn{2}{|c|}{ TPGC } & \multicolumn{2}{|c|}{ TENA } \\
\hline & 2019 & 2020 & 2019 & 2020 \\
\hline Average Return & $\overline{-} .0496 \%$ & $2.7054 \%$ & $\overline{-} .0867 \%$ & $\overline{-} .4307 \%$ \\
\hline Risk (VaR 95\%) & $4.749 \%$ & $19.092 \%$ & $2.8246 \%$ & $5.6839 \%$ \\
\hline mRVAL & -0.02532 & 0.13801 & -0.05572 & -0.08821 \\
\hline Average Price & 1.56 & 5.45 & 13.23 & 11.52 \\
\hline $\begin{array}{l}\text { Average of } \\
\text { Selling Volume }\end{array}$ & 71499.04 & 268385.8 & 21647.69 & 24408.46 \\
\hline
\end{tabular}

\section{CONCLUSION}

The TPGC has been shown to achieve the highest risk-adjusted return during the COVID-19 outbreak (2020) among other shariah constituencies listed on the top 10 market capitalization of FTSE Russel's version. Moreover, the buy and sell signals of TPGC generated by EMA analysis fell in the last four months of 2020 with the longest holding period of 209 days. This implies that during the pandemic, investors are advised to prefer to avoid selling/buying activities.

The performance of TPGC before and in the middle of the outbreak showed significant growth. The comparison involves several indicators like average return, average price, risk-adjusted return, and average selling volume. This growth is likely due to the increase in market demand for health care equipment in the prevention and handling of the
COVID-19 outbreak and is predicted to remain high in the future, due to disaster uncertainty, especially for all stocks in the health sector. Conversely, most of shariah stocks listed on the top 10 market capitalization of FTSE Russel's versions is more volatile during the mid-outbreak than the preoutbreak.

\section{ACKNOWLEDGMENTS}

We would like to gratitude for the support provided by Department of Mathematics, UIN Sunan Kalijaga and Department of Mathematical Sciences, Universiti Teknologi Malaysia. We also thank the anonymous referees for their useful suggestions.

\section{REFERENCES}

[1] C. F. S. Ng, X. T. Seposo, M. L. Moi, M. A. B. A. Tajudin, L. Madaniyazi, and M. 
Sahani, "Characteristics of the COVID-19 epidemic and control measures to curb transmission in Malaysia," Int. J. Infect. Dis., vol. 101, pp. 409-411, 2020.

[2] L. Rampal and L. B. Seng, "Malaysia's third COVID-19 wave - a paradigm shift required," Med. J. Malaysia, vol. 76, no. 1, pp. $1-4,2021$.

[3] N. A. Aziz, J. Othman, H. Lugova, and A. Suleiman, "Malaysia's approach in handling COVID-19 onslaught: Report on the Movement Control Order (MCO) and targeted screening to reduce community infection rate and impact on public health and economy," J. Infect. Public Health, vol. 13, no. 12, pp. 1823-1829, 2020.

[4] A. Hagen, "How Dangerous Is the Delta Variant (B.1.617.2)?," 2021

[5] W. F. Sharpe, "The Sharpe Ratio," J. Portf. Manag., vol. 21, no. 1, pp. 49-58, 1994.

[6] N. S. M. Mussafi and Z. Ismail, "Quadratic Programming for Optimizing the Diversified Shariah Stock Portfolio," Adv. Soc. Sci. Educ. Humanit. Res., vol. 474, no. Isstec 2019, pp. 139-147, 2020.

[7] K. Dowd, "Adjusting for risk: An improved sharpe ratio," Int. Rev. Econ. Financ., vol. 9, no. 3, pp. 209-222, 2000.

[8] S. Plastira, "Performance Evaluation of Size, Book-to-Market and Momentum Portfolios," Procedia Econ. Financ., vol. 14, no. 14, pp. 481-490, 2014.

[9] D. V. Malakhova, A. A., Starova, O. V., Yarkova, S. A., Danilova, A. S., Zdanovich, M. Y., Kravtsov, D. I., \& Zyablikov, "Reward-to-Variability Ratio as a Key Performance Indicator in Financial Manager Efficiency Assessment. In Computer Science On-line Conference." Springer, Cham., pp. 598-613, 2020.

[10] S. Hansun, "A new approach of moving average method in time series analysis," 2013 Int. Conf. New Media Stud. CoNMedia 2013, 2013.

[11] N. S. M. Mussafi and Z. Ismail, "A Review on Shariah Stock Portfolio Optimization," DLSU Bus. Econ. Rev., vol. 31, no. 1, pp. 142-157, 2021.
[12] A. Raudys and Ž. Pabarškaitè, "Optimising the smoothness and accuracy of moving average for stock price data," Technol. Econ. Dev. Econ., vol. 24, no. 3, pp. $984-$ 1003, 2018.

[13] N. Eiamkanitchat, T. Moontuy, and S. Ramingwong, "Fundamental analysis and technical analysis integrated system for stock filtration," Cluster Comput., vol. 20, no. 1, pp. 883-894, 2017.

[14] FTSE Russel, "Factsheet of FTSE Bursa Malaysia EMAS Shariah Index,” 2020.

[15] Bank Negara Malaysia, "Interest Rate," 2020.

[16] N. A. Harish, S. K. M. Hairullah, S. A. Bakar, and K. Abd Rahman, "Fuzzy Golden Cross and Fuzzy Death Cross as Stock Market Forecasting Indicator," ASM Sci. J., no. 6, pp. 120-124, 2019. 